\title{
Interactive comment on "Toward a variational assimilation of polarimetric radar observation in a convective scale NWP model" by Guillaume Thomas et al.
}

\section{Guillaume Thomas et al.}

guillaume.thomas@meteo.fr

Received and published: 13 February 2020

First of all, I wanted to acknowledge for the comments which helped to improve the manuscript.

Concerning the typo at line 325, it is corrected as follow: "Concerning ZDR, first guess and observation distributions (Fig. 7c and d respectively) appear to be quite different."

Concerning the Figure $7, \mathrm{I}$ took your advice in consideration by adding more space between the different sub-figures, and by printing titles with bold font only. I also applied the same corrections for the Figure 8 (see figures attached with this present answer). 
Interactive comment on Atmos. Meas. Tech. Discuss., doi:10.5194/amt-2019-462, 2019.

Interactive comment 
AMTD
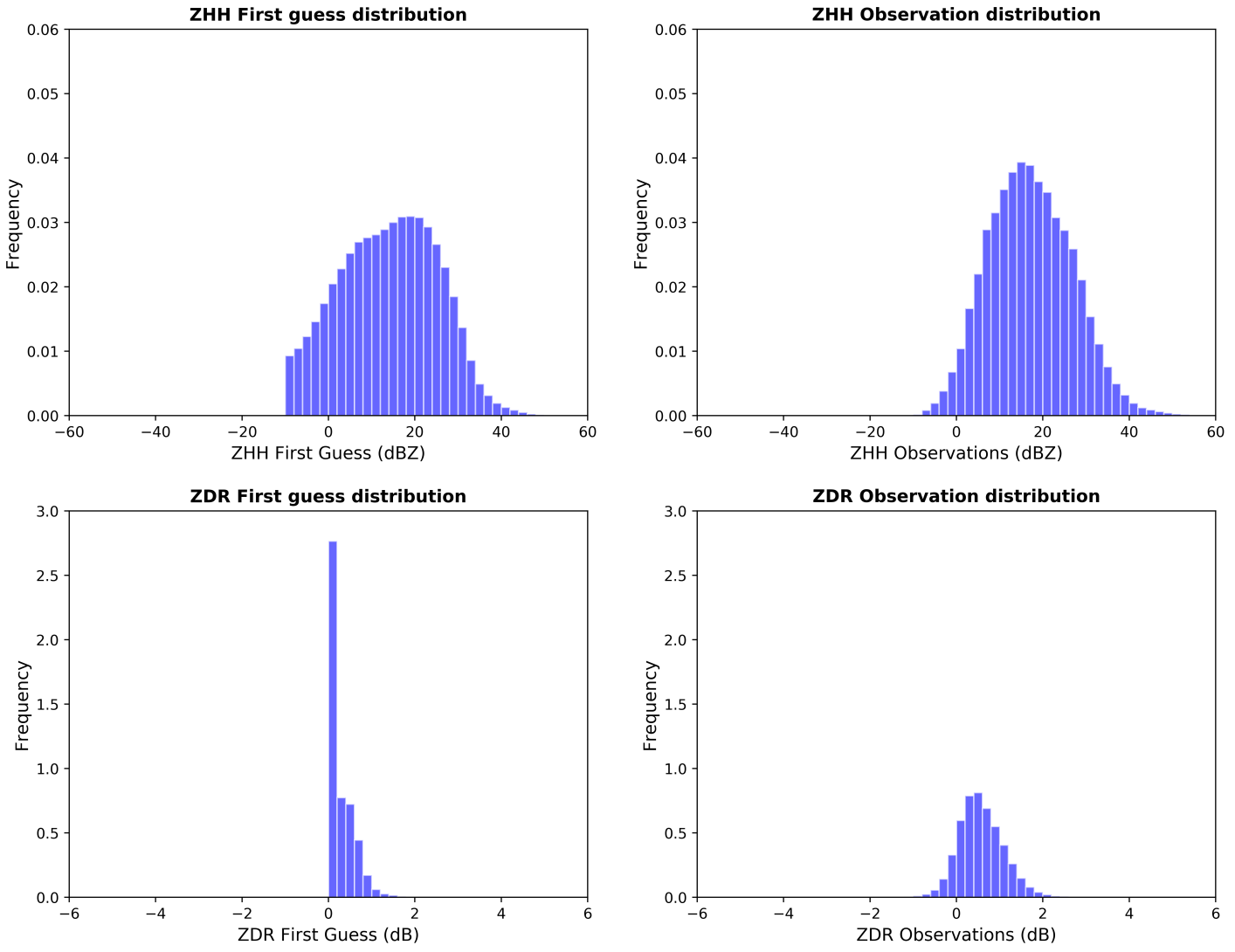

\section{Interactive comment}

Fig. 1. 
AMTD

a)

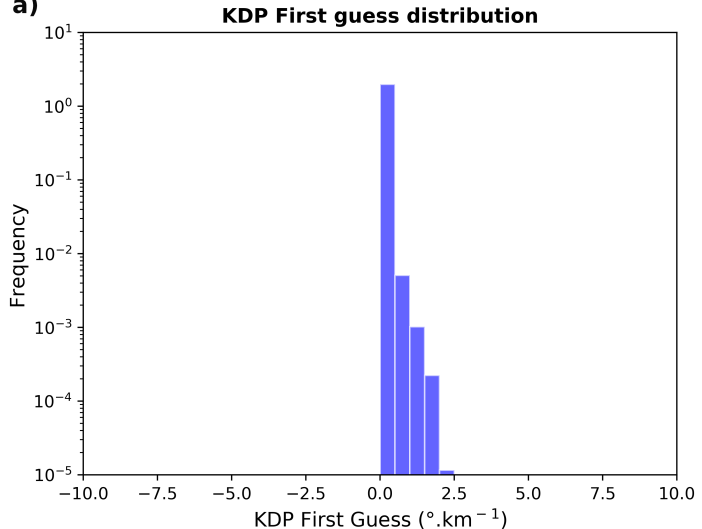

c)

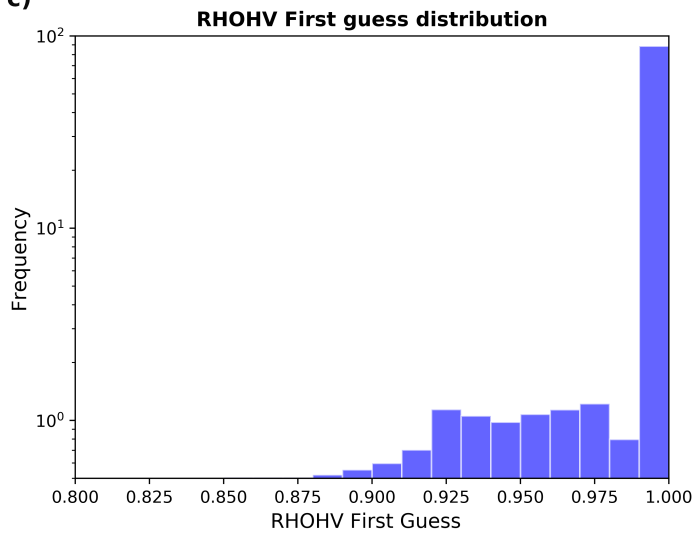

b)

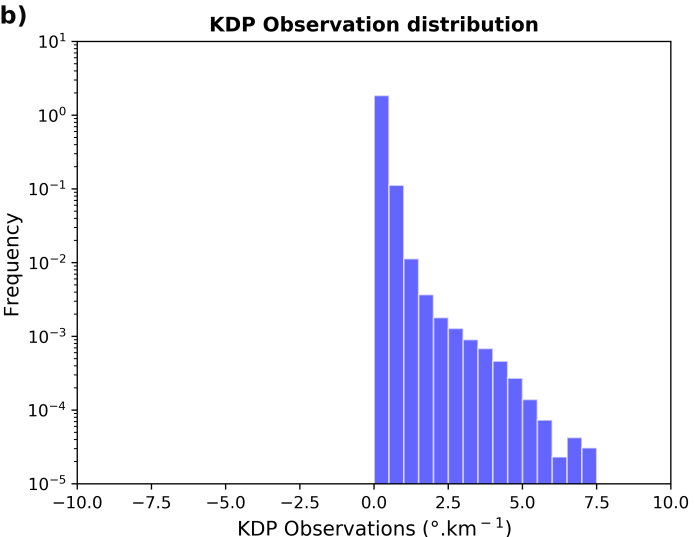

d)

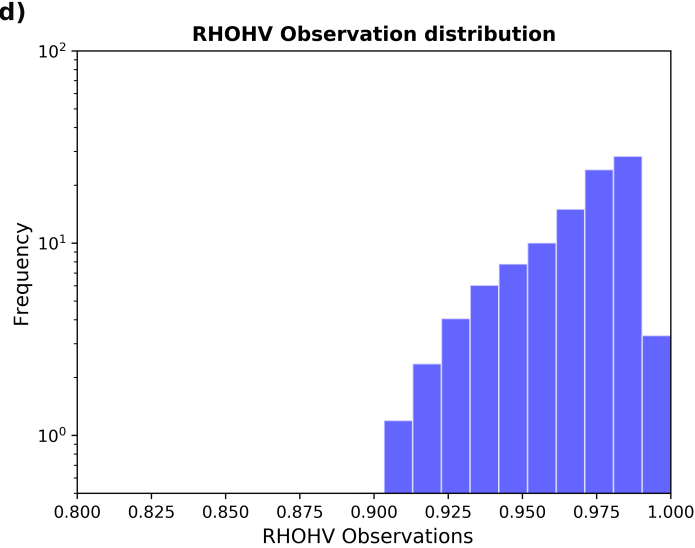

Interactive comment

Discussion paper 